\title{
A novel retrieval method using a Cusco speculum for large colorectal resection specimens following endoscopic treatment
}

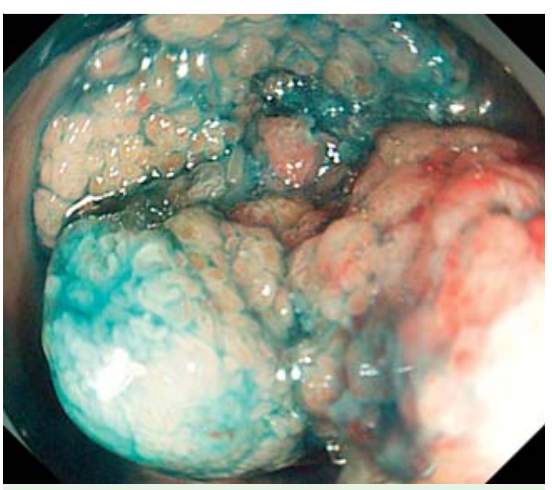

Fig. 1 Endoscopic submucosal dissection of an early rectal cancer being performed in a 70-year-old man.

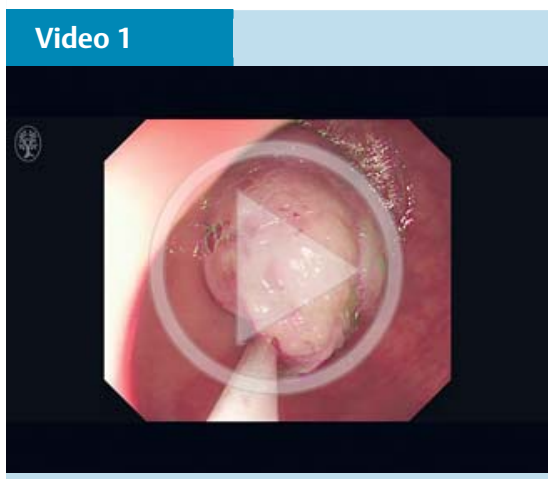

The specimen within the rectum was grasped with the retrieval net, before being retrieved via a Cusco speculum that had previously been carefully inserted into the anus to dilate the anal canal.

Endoscopic submucosal dissection (ESD) was performed for early rectal cancer in a 70-year-old man ( $\bullet$ Fig. 1). The bulky tumor occupied nearly half of the lumen. As the forcible removal of the resected specimen from the rectum using only the retrieval net (Disposable Loop Retrieval Net; net diameter $40 \times 75 \mathrm{~mm}$; Meditalia, Palermo, Italy) could have resulted in its fragmentation, we decided to take a different approach.

The endoscope was withdrawn from the patient's body, so that it could be passed through a Cusco speculum ( $\bullet$ Fig.2). When the endoscope was reinserted into the rectum, the specimen was grasped with the retrieval net. The Cusco speculum was then carefully inserted into the anus to dilate the anal canal and retrieve the specimen ( $\bullet$ Fig. 3; $\bullet$ Video 1 ). The actual

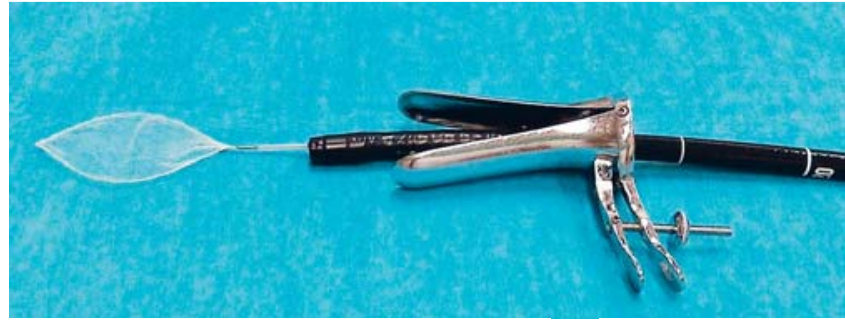

Fig. 2 The endoscope passing through a Cusco speculum, with the retrieval net inserted through the endoscope.

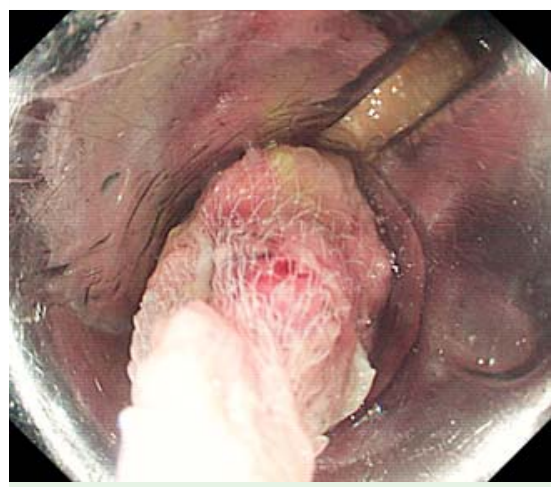

Fig. 3 The en bloc specimen being retrieved through the Cusco speculum.
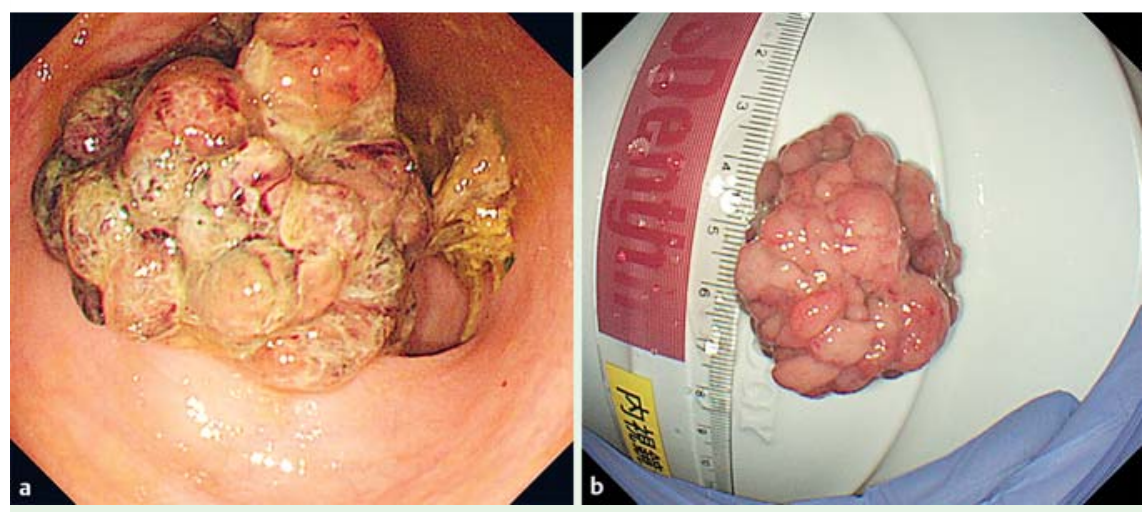

Fig. 5 The large polyp that was also identified: $\mathbf{a}$ in endoscopic view; $\mathbf{b}$ following retrieval, when it was found to be approximately $50 \mathrm{~mm}$ in diameter.

size of the specimen was $50 \times 45 \mathrm{~mm}$ in diameter and the height of the raised portions was $25 \mathrm{~mm}$ ( $\bullet$ Fig. 4). In this way, the specimen was retrieved undamaged and there were no complications due to the procedure.

ESD is the gold standard for en bloc excision of large colorectal tumors. After ESD, the whole specimen must be retrieved in order to ensure that correct pathological evaluation can be performed. In the lower gastrointestinal tract, the anal canal is the narrowest portion because of the pres-

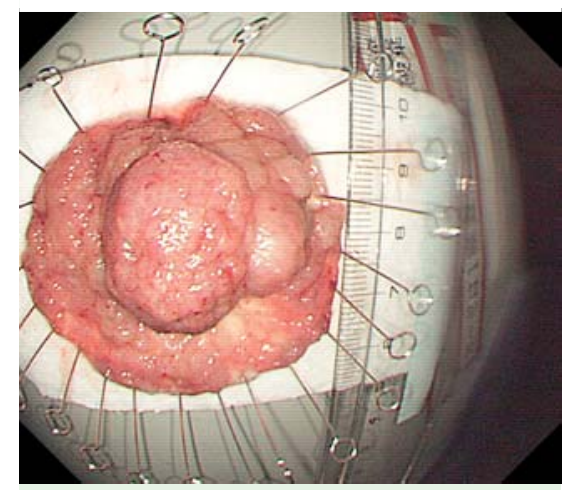

Fig. 4 The retrieved specimen, which was $50 \times 45 \mathrm{~mm}$ in size, with a height in the raised portions of $25 \mathrm{~mm}$ ence of the anal sphincter. During the retrieval process, the specimen can easily be fragmented because of the tightening force of this muscle. Various techniques have therefore been devised to retrieve large specimens without damaging them [1-3].

In this study, we used a Cusco speculum, which is frequently used in the obstetrics and gynecology department of any hospital and can be reused repeatedly. Furthermore, the procedure did not adversely affect the patient. It has been reported 
that, during transanal surgery under general anesthesia, the anal sphincter was damaged, leading to various degrees of incontinence, in approximately $20 \%$ of patients when the anal canal was stretched to a diameter of $4 \mathrm{~cm}$ [4], while damage to the anal sphincter was not seen when the anal canal was dilated up to $3 \mathrm{~cm}$.

In our case, the anal canal was dilated to approximately $3 \mathrm{~cm}$ with the patient under conscious sedation and the specimen was retrieved without any adverse events. This method was used not only to retrieve the large ESD specimen but also to retrieve a huge polyp that was resected by endoscopic mucosal resection (EMR) ( Fig.5). In summary, dilation of the anal canal using a Cusco speculum was found to be both safe and effective for the retrieval of specimens resected by EMR and ESD.

Endoscopy_UCTN_Code_CPL_1AJ_2AD

Competing interests: None
Yosho Fukita, Takefumi Takeda, Michifumi Toyomizu, Seitaro Adachi, Ikuma Yasuda, Tsutoshi Asaki, Hiroyuki Ishibashi

Department of Gastroenterology, Seirei Yokohama Hospital, Yokohama, Japan

\section{References}

1 Tanaka S, Toyonaga T, East J et al. Endoscopic retrieval method using a small grip-seal plastic bag for large colorectal resection specimens after endoscopic submucosal dissection. Endoscopy 2010; 42: E186 -E187

2 Ikehara H, Saito Y, Uraoka $T$ et al. Specimen retrieval method using a sliding overtube for large colorectal neoplasm following endoscopic submucosal dissection. Endoscopy 2015; 47: E168-E169

3 Nemoto D, Hayashi $Y$, Utano $K$ et al. A novel retrieval technique for large colorectal tumors resected by endoscopic submucosal dissection: tumor extraction by defecation. Endosc Int Open 2016; 4: E93 - E95

4 Karakayali FY, Tezcaner T, Moray G. Anorectal function and outcomes after transanal minimally invasive surgery for rectal tumors. J Minim Access Surg 2015; 11: 257 262
Bibliography

Dol http://dx.doi.org/ 10.1055/s-0042-117713 Endoscopy 2016; 48: E336-E337 (c) Georg Thieme Verlag KG Stuttgart · New York ISSN 0013-726X

Corresponding author Yosho Fukita, MD, PhD Department of Gastroenterology Seirei Yokohama Hospital 215 Iwai-cho, Hodogaya-ku Yokohama

Kanagawa 240-8521 Japan Fax: +81-45-7153387 yfukita@sis.seirei.or.jp 